\title{
Do attackers have a legal duty of care? Limits to the 'individualization of war'
}

\author{
Janina Dill ${ }^{1,2 *}$ \\ ${ }^{1}$ Associate Professor, Department of Politics and International Relations, University of Oxford, Oxford, \\ UK and ${ }^{2}$ Professorial Fellow, Nuffield College Oxford, Oxford, UK \\ ${ }^{*}$ Corresponding author. Email: Janina.Dill@nuffield.ox.ac.uk
}

(Received 2 April 2017; revised 19 March 2018; accepted 23 October 2018)

\begin{abstract}
Does International Humanitarian Law (IHL) impose a duty of care on the attacker? From a moral point of view, should it? This article argues that the legal situation is contestable, and the moral value of a legal duty of care in attack is ambivalent. This is because a duty of care is both a condition for and an obstacle to the 'individualization of war'. The individualization of war denotes an observable multi-dimensional norm shift in international relations. Norms for the regulation of war that focus on the interests, rights, and duties of the individual have gained in importance compared to those that focus on the interests, rights, and duties of the state. As the individual, not the state, is the ultimate locus of moral value, this norm shift in international relations, and the corresponding developments in international law, are morally desirable. When it comes to IHL, the goal of protecting the interests of the individual creates strong reasons both for and against imposing a legal duty of care on the attacker. The enquiry into whether IHL does and should impose a legal duty of care therefore reveals that the extent to which war can be individualized is limited.
\end{abstract}

Keywords: International Humanitarian Law; proportionality; distinction; duty of care; individualization of war; targeting

Does International Humanitarian Law (IHL) impose a duty of care on the attacker? From a moral point of view, should it? This paper argues that the legal situation is contestable, and the moral value of a legal duty of care in attack is ambivalent. This is because a duty of care is both a condition for and an obstacle to the individualization of war'. The individualization of war denotes an observable multidimensional norm shift in international relations. Norms for the regulation of war that focus on the interests, rights, and duties of the individual have gained in importance compared to those that focus on the interests, rights, and duties of the state. As the individual, not the state, is the ultimate locus of moral value, this norm shift in international relations is morally desirable. When it comes to IHL, the goal of protecting the interests of the individual in war creates strong reasons both for and against imposing a legal duty of care on the attacker. This enquiry into 
whether IHL does and should impose a duty of care therefore reveals that the extent to which war can be individualized is limited.

Before examining whether IHL does or should impose a duty of care in attack, we need to clarify what it is. In tort law, a duty of care is an obligation to take steps that are reasonably sufficient to achieve or avoid a specific outcome. ${ }^{1}$ It is a second-order obligation not to be negligent in discharging a first-order obligation (McBride and Bagshaw 2005, 51). For instance, IHL's principle of distinction imposes a first-order obligation on attackers not to target civilians, but to direct all attacks against military objectives. A second-order obligation would concern the degree of attention and effort that an attacker has to invest in making sure that their intended target is indeed a military objective. A duty of care is a particularly demanding type of second-order obligation. It would require that an attacker takes all the steps that a reasonable observer would deem sufficient to ensure that the target is not civilian. If a reasonable observer would not be confident about a target's status, the attacker would have to refrain from releasing her weapon.

Why does it matter whether IHL imposes a duty of care in attack? Under two conditions, law's ability to achieve its regulative goals depends on a duty of care. First, if law has goals that regularly come into tension with each other, a duty of care can ensure that both are reflected, to a specified minimum extent, in the outcome of law-guided conduct. A duty of care achieves this by making the permission of conduct that serves one goal conditional on a sufficient effort to safeguard the other. Second, a duty of care can cure volitional defects. Volitional defects are incentive structures that account for why individuals systematically fail to properly discharge their first-order obligations (see, for instance, Tasioulas 2010, 101). For instance, when law has high compliance costs, individuals are tempted to cut corners. A duty of care, which often signals that negligent violations of first-order obligations incur sanctions, provides a counter-veiling incentive. Both conditions under which law depends on a duty of care for its effectiveness - contradictory objectives and volitional defects - obtain in the regulation of warfare.

It is well appreciated that IHL has contradictory regulative goals: allowing military operations to proceed, on the one hand, and protecting civilians from the dangers of combat, on the other. IHL's core provisions reflect this tension because IHL does not shield civilians from all harm. Instead, the principles of distinction, necessity, and proportionality only protect civilians against intentional, unnecessary, and excessive harm, respectively. Even these limited protections, however, systematically hamstring belligerents' pursuit of victory. In turn, every time an attacker permissibly engages the enemy, these protections are put at risk. Moreover, attackers have very few incentives to invest attention and effort into discharging even their limited first-order obligations. In the midst of combat operations, an additional step to verify a target's status may well put the attacker's life at risk. Given IHL's need to allow the engagement of the enemy and the volitional defects in attackers' incentive structures, IHL's ability to effectively protect civilians in war depends on its imposing a duty of care in attack.

From a moral point of view, it seems then, IHL should impose a duty of care. Indeed, the paper will argue that this is a necessary condition for the individualization of war. However, a duty of care is also highly demanding on the individual charged

\footnotetext{
${ }^{1}$ Goldberg and Zipursky (2007), Honoré (1988), Perry (1992), Waldron (1995). For an overview of different definitions of a duty of care in tort law, see also Hylton (2016).
} 
with delivering it. The very conditions of battle, which make IHL's protective capacity dependent on the imposition of a second-order duty of care, also undermine the reasonable attacker's capacity to discharge this obligation. I will argue that it would be too much to ask of the individual attacker ${ }^{2}$ - frightened and threatened in the proverbial fog of war - to determine what steps a reasonable observer would consider sufficient to bring about a specific outcome. In the answer to the question of whether IHL should impose a legal duty of care hence crystallizes a dilemma: international law cannot give the individual her legal due in war as both a beneficiary of effective protections and an embattled agent with correspondingly limited duties.

How does IHL currently stand on this dilemma; does it recognize a duty of care in attack? The First Additional Protocol to the Geneva Conventions ${ }^{3}$ demands that in 'the conduct of military operations, constant care shall be taken to spare the civilian population' (Art 57(1) API). Although the provision features the term 'care', this paper shows that the principles concerned with the outcome of an attack - necessity and proportionality - are not subject to a second-order duty of care. ${ }^{4}$ Article 57 demands that the attacker should take 'all feasible precautions' in attack. What is feasible may be less than what is reasonably sufficient to ensure that civilians will not have been harmed unnecessarily or excessively when the dust sets on the rubble after an attack. Moreover, with the principle of proportionality, IHL makes it impossible to establish what unlawful consequences of an attack look like. Even if IHL recognized a legal duty of care in attack, it would therefore be unclear what outcome the reasonable, non-negligent attacker ought to strive for. This legal uncertainty is reflected in International Criminal Law's (ICL) contested scope of the mens rea required for unlawful attack.

The argument proceeds in six steps. The first section describes the individualization of war and the political imperative it creates: IHL's beneficiary and addressee ought to be the individual. I will argue that this is also morally desirable. The section further shows that the individualization of war creates strong reasons both for and against imposing a legal duty of care in attack. Sections two to four systematically uncover the scope of the second-order obligations that Article 57 of the First Additional Protocol imposes on the attacker to realize the protections afforded by the principles of distinction, necessity, and proportionality, respectively. Each section highlights the contestability of these second-order duties. I will show how they fall short of a proper legal duty of care in attack. The fifth section enquires into the mens rea of the crime of unlawful attack and reveals its fragmentation. In the final section, I will argue that the uncovered moral ambivalence and legal uncertainty that surround the duty of care in attack reveal the limits of war's individualization.

\footnotetext{
${ }^{2}$ The term 'attacker' denotes combatants that act as 'trigger pullers' in the sense that they directly engage the enemy during the conduct of hostilities. Not all individuals with the legal status of combatant necessarily act as attackers. Some fulfill logistics rather than combat roles. Other combatants are higher up in the chain of command and do not themselves launch attacks. I will address the role of these commanders in discharging a duty of care in attack in the final section of this paper.

${ }^{3}$ Protocol Additional to the Geneva Conventions of 12 August 1949 Relating to the Protection of Victims of International Armed Conflicts, 8 June 1977 (herein API or the First Additional Protocol).

${ }^{4}$ I will argue that attackers incur a duty of care in distinguishing between civilians and combatants. However, the outcome that an attacker has to manage when complying with this duty is not the outcome of the attack itself, as would be the case if the principles of necessity or proportionality were subject to a duty of care. It is merely the outcome of an attacker's deliberations as to the direction of her fire.
} 


\section{The individualization of war and a legal duty of care in attack}

What do the increase in UN peacekeeping mandates for the protection of civilians, the United States' growing resort to targeted killings outside areas of active hostilities, and the International Criminal Court's (ICC) issuing of an arrest warrant for the sitting President of Sudan have in common? They are manifestations of a multi-dimensional norm shift regarding the regulation of war in international relations. This paper refers to this shift as the 'individualization of war'. ${ }^{5}$ The individualization of war consists of a decrease in the importance of international norms for the regulation of war that focus on the interests, rights, and duties of the state and the increase in the importance of norms for the regulation of war that focus on the interests, rights, and duties of individuals. International norms for when and how war ought to be waged more and more take the individual, not the state, to be their addressee and beneficiary.

Several developments in international law form part of the individualization of war. ${ }^{6}$ General international law now recognizes large-scale violations of individual rights as providing grounds for resort to force. In the aftermath of war, ICL holds the individual to account directly in virtue of international law. As cases against individuals before tribunals and courts have proliferated, invocations of state responsibility for the unlawful use of force have declined in prevalence (Sikkink 2011). In addition, international adjudicative bodies increasingly apply human rights law to situations of armed conflict (Droege 2007; Milanović 2016). The proposition that the individual retains rights, even in the midst of war, has in turn created interpretive pressure for IHL to better protect individuals during hostilities. One example of such interpretive pressure is the demand that IHL should recognize a prohibition on killing combatants if capture is possible. ${ }^{8}$

Each mentioned legal development has attracted scholarly and real-world opposition. The individualization of war does not progress linearly. It nonetheless enjoys considerable momentum because, in its course, international norms and laws change in a morally desirable way. Individualized norms and laws for the regulation of war better reflect that the individual, not the state, is the ultimate locus of moral value. ${ }^{9}$ Moral individualism, in turn, is at the heart of an 'extraordinarily expansive and authoritative ... globalizing ideology' (Elliott 2007, 344; Dumont 1986). International relations scholarship has shown, for instance, that appeals to individual physical integrity rights are ever more cross-culturally effective as tools for political mobilization (Forsythe 2006; Reus-Smit 2013). That international law should focus on the interests, rights and duties of the individual is therefore both a moral goal and a growing political imperative in international relations.

If for moral and political reasons the beneficiary of IHL ought to be the individual, IHL must seek to protect civilians from the harmful effects of combat.

\footnotetext{
${ }^{5}$ Although the mentioned phenomena are subject to extensive debates in international relations and legal literature, they are rarely explained as forming part of a single trend. To my knowledge, the term 'individualization of war' to denote these developments appears in three existing texts: Blum (2014), Voelz (2015), Welsh (2014).

${ }^{6}$ For discussions of some of these developments, see Issacharoff and Pildes (2013), Meron $(2000,239)$, Teitel (2002).

${ }^{7}$ The legality of unilateral humanitarian intervention is as contestable as ever, but the recognition of purely internal conflicts as constituting 'a threat to the peace, breach of the peace or act of aggression', in accordance with Article 39 UN Charter, is rarely contested.

${ }^{8}$ Blum (2010, 48), Dill (2015), Haque (2017). For a critical appraisal, see Ohlin (2013a, 1268f).

${ }^{9}$ For full accounts of morally justified conduct in war based on reductive individualism, see Fabre (2012), McMahan (2009).
} 
Indeed, this is one of IHL's recognized regulative goals. At the same time, IHL must not make wars too difficult to wage, lest it be ignored by belligerents on the ground. Due to the need to accommodate these contradictory objectives - allowing combat operations to proceed and protecting civilians - IHL protects civilians to a limited extent. The principles of distinction, necessity, and proportionality permit killing civilians, if this is foreseen, necessary and non-excessive. Even these limited protections against intentional, avoidable, and disproportionate harming, however, risk being jeopardized every time an attacker engages the enemy. If law permits conduct that is inherently threatening to legally protected interests, ${ }^{10}$ attaching a duty of care to the permission of this conduct ensures that law remains effective in protecting these interests, the permission notwithstanding. If the individual civilian caught up in the midst of hostilities is meant to be an effective beneficiary even just of limited legal protections, IHL therefore ought to impose a duty of care on the attacker.

Moreover, attackers tend to start from a place of imperfect information about their targets and the context of an attack. This systematic lack of information means that the constraining force of first-order legal obligations crucially hinges on how hard the attacker tries to fulfill them. At the same time, taking an additional step to protect the interests of enemy civilians will regularly mean that an attacker increases the risk to her own life. This zero-sum logic between the protection of civilians and an attacker's vital interests creates a volitional defect: it incentivizes the attacker to cut corners in the compliance with law rather than to try hard to discern the implications of her first-order obligations. This non-contingent reality of war makes the protective capacity of IHL dependent on second-order obligations. Without a legal duty of care in attack the individualization of war therefore remains partial.

This same non-contingent reality of war, however, also provides a strong reason against IHL's recognizing a duty of care because it curbs the individual attacker's moral agency. ${ }^{11}$ Moral agency, as understood here, has three dimensions: first, the capacity to make reasoned distinctions between right and wrong, second, the ability to make this judgment in a given situation and, third, the capacity to act according to one's own reasons. First, physical exhaustion, mortal danger, the loss of comrades, and narratives that dehumanize the enemy are among the conditions that diminish the human capacity to tell right from wrong. ${ }^{12}$ Second, even if a combatant retained her ability to make reasoned judgments in principle, the secrecy surrounding many states' national security policies, the hierarchical nature of military decision-making, the complexity and pace of modern military operations all contribute to the proverbial fog. As a result, individuals regularly lack the information necessary to assess their choices or predict the consequences of their actions. ${ }^{13}$ Third, the integration of the individual into a military chain of command

\footnotetext{
${ }^{10}$ It is contested whether individuals themselves hold rights not to be harmed intentionally, avoidably or excessively in virtue of IHL or whether IHL merely protects civilians' interest in these limited protections. For the purposes of this argument, nothing hinges on whether an attacker's duties are mirrored in rights held by the individual civilian or by the opposing belligerent. For the view that IHL bestows rights directly onto the individual, see Sandoz et al. (1987, \$79), Greenwood (2008, \$134), Meron (2000, 240), Wolfrum (2008, \$1434). For the opposing position, see Berster (2010, 627), Parlett (2011).

${ }^{11}$ It is widely appreciated that the stresses of battle 'degrade human capacities for reason and restraint' Crawford (2013, 226, 66ff and 245ff). Similar, Isaac (2011, 6), May (2007, 11), Walzer $(1977,306)$.

${ }^{12}$ Similar Crawford (2013, 248 and 256), McMahan (2009, 127).

${ }^{13}$ For this argument, see also Dill $(2013,315)$.
} 
means that individuals may be systematically unable to act according to their own reasons. $^{14}$

If IHL seeks to safeguard the interests of individuals in war, it should take account of these limitations to combatants' moral agency. ${ }^{15}$ A duty of care, in contrast, admits of no limitations to the attacker's moral agency. It is as demanding as law can be regarding an individual's capacity to make future oriented judgments about the implications of her actions. In order to fulfill a duty of care, the individual has to determine what actions a reasonable observer would consider sufficient to secure the desired outcome. In war, a duty of care would demand that the attacker figures out what it takes to meet an objective standard of reasonable certainty regarding the status of her target and the consequences of her attack. Then she would have to achieve this level of knowledge or refrain from attacking. A duty of care is furthermore associated with a particularly low threshold for legal responsibility for the consequences of one's actions. It often signals that negligent violations of law can trigger individual responsibility. ${ }^{16}$

As counterintuitive, possibly even unreasonable, as it may therefore seem from the point of view of the individual attacker that IHL would impose a duty of care, as counterintuitive and even unreasonable it may seem from the point of view of the individual civilian that IHL would legally privilege potentially lethal attacks without demanding that the attacker takes sufficient care when launching them. If IHL's moral and political goal is the effective guidance and protection of the individual in war because IHL's addressee and beneficiary ought to be the individual, IHL faces a dilemma: The effective guarantee of even limited civilian protections in the midst of battle would require imposing a duty of care on the attacker. The recognition of the limits to the individual attacker's moral agency in the non-contingent reality of war, however, requires not imposing such a duty. How does IHL currently stand on this dilemma; does it recognize a duty of care in attack?

\section{A duty of care in distinction?}

To recall, the bearer of a duty of care has to take the steps that a reasonable observer would deem sufficient to ensure that her conduct will not result in an outcome that contravenes her first-order obligation. ${ }^{17}$ Article 57 of the First Additional Protocol enjoins belligerents to take 'constant care' to spare civilians. The commentary argues that the provision 'reaffirms rules which are already contained explicitly or implicitly in other articles' (Sandoz et al. 1987, \$2189). It spells out second-order obligations concerning the implementation of an attacker's first-order obligations. ${ }^{18}$ The most fundamental such first-order obligation is the

\footnotetext{
${ }^{14}$ Similar, Bohrer $(2012,1)$, May (2007, 4 and 171).

${ }^{15}$ The very subjection of warfare to legal regulation, of course, presupposes that individuals in war have some moral agency. Law constitutes its addressees as subjects capable, in principle, of bearing rights and duties. A legal subject has to have the three mentioned capacities that constitute moral agency (to make judgments, to assess her choices, and to act according to her reasons) in order to effectively discharge legal duties.

${ }^{16}$ Section $\mathrm{V}$ returns to this issue.

${ }^{17}$ See, for instance, Caparo v. Dickman (1990, 2 AC 605); Wright (2001, 87). According to Hylton (2016, $122 \mathrm{f}$ ), a duty of care can arise based on an agent's prior conduct or the relationship between the duty bearer and the beneficiary of law's protections. Alternatively, it can be statutory.

${ }^{18}$ The next section will argue that there is one exception. Article 57 contains the first-order obligation to minimize expected incidental civilian harm to what is necessary in order to achieve a given military advantage.
} 
requirement to 'distinguish between the civilian population and combatants and between civilian objects and military objectives and ... [to] direct ... operations only against military objectives' (Article 48 API). ${ }^{19}$ The second-order duty corresponding to the principle of distinction demands that 'those who plan or decide upon an attack shall do everything feasible to verify that the objectives to be attacked are neither civilians nor civilian objects' (Article 57(2) a [i] API). Does this second-order obligation amount to a duty of care in distinction?

Article 57 ensures that the principle of distinction is not satisfied as soon as an attacker selects a military objective for attack and programs the targeting pod accordingly. The attacker also has to take 'all feasible' steps to ensure that what she is aiming at is actually a military objective. What counts as a feasible step depends on what an attacker is legally obligated to sacrifice for the aim of verifying the status of her target. Some measures of intelligence gathering may be infeasible unless an attacker exposes herself to potential harm. Other measures are beyond reach given the technology available to the attacker. They would become feasible if a belligerent invested in intelligence surveillance and reconnaissance (ISR) capabilities. Moreover, the feasibility of verification measures may also depend on whether an attacker is ready to assume the risk that the operation will fail to yield the desired military advantage.

The parameters of feasibility according to Article 57 are subject to significant controversy. Although it is virtually uncontested that combatants have to assume some risk in order to verify the status of their target, views diverge as to how much exposure to potential harm combatants must accept. ${ }^{20}$ Similarly, it is controversial whether a belligerent has to acquire a minimum of ISR capabilities necessary to establish that a target is not civilian. ${ }^{21}$ Whether capabilities that are already available to the attacker have to be used to ensure that an attack is directed against a military objective is likewise contested. ${ }^{22}$ Finally, a measure that certainly undermines the military goal of an attack would reasonably be considered infeasible. It is unclear, however, whether an additional step to verify the status of a target must be considered feasible if it just somewhat decreases the likelihood of an attack's success. ${ }^{23}$

${ }^{19} \mathrm{An}$ attacker has to positively identify a military objective as target every time she launches an attack. A failure to direct one's attack anywhere in particular is also captured as a violation of IHL by the rule prohibiting indiscriminate attacks in Article 51(4) a and b API.

${ }^{20}$ The Law of War Manual of the United Kingdom Ministry of Defence acknowledges the legal uncertainty: 'The Law is not clear as to the degree of risk that the attacker must accept (...)' $(2004, \$ 2.7 .1)$. For the position that the obligation does not imply that the attacker is 'bound to sustain unnecessary military losses only in order to spare enemy civilians', see Dinstein $(2016,168)$. Haque, in opposition, argues that 'soldiers must accept any personal or operational risks necessary to achieve the required level of certainty' $(2012,6)$. Luban $(2014,277)$ proposes, less stringently, to determine the feasibility of verification with a view to the marginal increase in risk a measure causes to combatants compared to the marginal decrease in risk it implies for civilians.

${ }^{21}$ It is a minority position that belligerents have to procure the best available ISR technology to verify the status of their targets. In their Commentary to API Sandoz et al. accept that '[s] ome belligerents might have information owing to a modern reconnaissance device, while other belligerents might not have this type of equipment’ (1987, \$2199). Similar UK, Reservations and Declaration Made on Ratification (1998, \$I[c]).

${ }^{22}$ For the view that the attacker does not necessarily have to employ the ISR technology actually available to her, see Schmitt $(2006,460)$.

${ }^{23}$ The UK, Reservations and Declaration Made on Ratification $(1998, \$ I[b])$ states that feasible is 'that which is practicable or practically possible, taking into account all circumstances ruling at the time, including humanitarian and military considerations'. Even though this position is repeated in several 
Even if we agreed on the conditions of feasibility, the individual attacker would still face the epistemic challenge of determining what is in fact feasible in a given situation. Let us assume that a $25 \%$ or greater reduction in the probability that an attack will achieve its military advantage rendered a measure infeasible for the purposes of Article 57. It might not be obvious whether an additional reconnaissance mission would reduce the likelihood of success to such an extent, for instance, by tipping off the persons to be attacked. At the same time, a standard like feasibility, which requires a future oriented judgment, is not unusual in law. The measure by which an individual's judgment would normally be assessed is reasonableness. If we knew what consequences make an action infeasible, we could judge the attacker's decision not to take a measure according to whether a reasonable observer would have expected this measure to result in these consequences. Article 57 can thus be read as demanding that an attacker takes all verification measures that a reasonable observer would consider feasible to verify the status of a target.

A duty of care, in contrast, would demand that an attacker takes all verification measures that a reasonable observer would consider sufficient to ensure that the target is a military objective. At first glance, taking 'all feasible' measures may sound more demanding than a duty of care. If an attacker does what is sufficient to ensure that a target is not civilian, but omits additional measures that were feasible, she would have discharged a duty of care all while failing to comply with the secondorder obligation spelled out in Article 57(2) a [i]. However, this is unlikely to matter, unless against her expectations, she was targeting a civilian and additional feasible verification measures could have revealed this. In hindsight, the existence of additional feasible verification measures might suggest that the measures taken were not in fact sufficient. The greater the uncertainty and room for contestation as to what is sufficient and feasible, the less reasonable it is for an attacker to stop at measures that are sufficient and to forgo additional verification measures that are feasible.

In practice, taking all feasible measures, as demanded by IHL, is therefore unlikely to be more demanding than a duty of care, that is, taking measures that are sufficient. The reverse, however, is possible. What if all feasible measures to verify the status of a target are together not sufficient to establish with reasonable certainty that the target is a military objective? A duty of care is associated with the expectation that in this case an agent would refrain from attack. Proceeding would be negligent or reckless. Nothing in Article 57, however, requires an attacker to have a minimum level of knowledge about the status of her target. Feasibility as the touchstone for the required verification effort means that whether an individual has done enough to fulfill her second-order obligation does not turn on the likelihood of an attack's being directed against a civilian or civilian object. Article 57(2) a [i] fails to establish a duty of care in distinction properly so-called.

Even if it is not stipulated, does IHL not imply that if all feasible verification measures were insufficient to rule out that an attack is aimed at a civilian target, an attack would be prohibited? Without such an implied duty of care, the provisions enshrining the principle of distinction would certainly be less apt to achieve the object and purpose spelled out in Article 51(1) API: Civilians 'shall enjoy general protection against dangers arising from military operations'. A purposive interpretation thus supports an implied second-order duty of care in

military manuals of different countries, Sandoz et al. $(1987, \$ 2198)$ critique it as 'too broad' in the Commentary to the Protocol. 
distinction. A systematic interpretation, however, casts doubt over such an implied duty to either take reasonably sufficient verification measures or refrain from attacking. Article 50(1) separately demands that in case of doubt a person shall be considered a civilian. If an obligation to only attack when reasonably certain about the status of a target were implied by Article 57, then Article 50(1) would be redundant. ${ }^{24}$

In turn, if we read Article 50(1) as establishing a prohibition on launching attacks against persons unless an attacker is reasonably certain about their status, then IHL does impose a duty of care in distinction vis-à-vis persons. However, with regard to objects, IHL still permits launching an attack, even after all feasible measures of verification have proven insufficient to ensure that the target is not a civilian object. $^{25}$ The Protocol hence establishes a proper duty of care in distinction between persons and with the help of Article 50(1). Article 57, even though it features the term 'constant care', imposes only a second-order duty to do what is feasible to avoid targeting a civilian object. This falls short of a duty of care in distinguishing military objectives from civilian objects.

\section{A duty of care to ensure the necessity of civilian harm?}

Distinction relates to the direction of an attack. The principle demands that an attacker verifies that the target identified for attack and aimed at is a military objective. The wording does not imply that the attacker has to verify that the object or person an attack ultimately kills/destroys is the intended target. The benchmark for discharging the duty to take care in distinction between persons is therefore not the outcome of the attack (i.e. who is killed), but the outcome of the attacker's deliberations (i.e. who is fired at). Does IHL impose second-order obligations geared towards securing the outcome of an attack? Paragraph 2 a subsection [ii] of Article 57 tasks combatants with taking 'all feasible precautions in the choice of means and methods of attack with a view to avoiding, and in any event to minimizing, incidental loss of civilian life, injury to civilians, and damage to civilian objects'. This prescription, however, does not concern the implementation of a first-order duty. It is itself a first-order duty. ${ }^{26}$ Article 57 spells out the principle that expected civilian harm has to be minimized to that which is necessary for the achievement of a given military advantage. ${ }^{27}$

This principle of necessity is noteworthy because it signals that causing the harmful outcome an attack risks causing, that is killing civilians, is not itself a reason not to engage in an attack. Instead, the risk of harmful consequences must

\footnotetext{
${ }^{24}$ Paragraph 4 of Article 57 requires 'reasonable' precautions during military operations at sea and in the air. This juxtaposition further corroborates the interpretation that the drafters did not by accident omit references to reasonableness in paragraphs $1-3$. They deliberately emphasized feasibility instead.

${ }^{25}$ Article 52(3) API demands that in case of doubt about whether or not an object is a military objective by use, it shall be presumed not to be so used. This amounts to a duty of care. However, it is a duty of care only toward objects that are military objectives by use, not toward those that are military objectives by nature, location, or purpose.

${ }^{26}$ It is rarely appreciated that the prescriptions to 'do everything feasible' play radically different roles in sub-sections [i] and [ii]. The latter establishes the first-order obligation to minimize civilian casualties. The former denotes the second-order obligation to discharge distinction, as discussed in Section II of this paper.

${ }^{27}$ Similar, The Israel High Court of Justice, Beit Sourik Village Council v. The Government of Israel, Judgment of 30 May 2004, HCJ 2056/04, \$41.
} 
merely be minimized. If the harmful consequences are likely to occur anyway, they must be reduced as much as possible. It follows that with this principle, IHL does not demand the reduction of the likelihood or magnitude of incidental harm below an absolute threshold. The Protocol does not define an outcome (i.e. a minimum standard of civilian protection) which must be achieved with reasonable certainty and which determines what measures a reasonable attacker should take. Instead IHL stipulates the measures a reasonable attacker should take (i.e. doing what is feasible to minimize expected harm). These measures, in turn, determine the outcome to be achieved: an attack is not legal if an opportunity to further reduce expected civilian harm was missed. ${ }^{28}$

Of course, IHL could in principle still attach a second-order duty of care to the principle of necessity. This would be an obligation to take steps that a reasonable observer would deem sufficient to ensure that there are no additional feasible measures that would further reduce civilian harm. Article 57 does not spell out such a second-order duty of care in minimizing civilian harm. Could it be implied? Taking 'all feasible' measures to mitigate expected harm certainly demands a positive causal intervention into the world on the part of the attacker. Rather than relying on her spontaneous belief that the expected civilian harm is necessary, an attacker has to explore whether a change in the weapon, the angle or the time of attack could reduce civilian casualties. A duty of care would in addition require that an attacker only launches an attack if she meets an objective minimum standard of reasonable certainty regarding the necessity of the expected civilian harm. Establishing with reasonable certainty that there were no measures to further reduce expected civilian harm would be epistemically challenging. It would, at minimum, be contestable that paragraph 2 implies such a demanding second-order duty without spelling it out.

Paragraph 3 of Article 57 casts further doubt over such an implied duty of care in discharging the principle of necessity. The provision adds that 'when a choice is possible between several military objectives for obtaining a similar military advantage, the objective to be selected shall be that the attack on which may be expected to cause the least danger to civilian lives and to civilian objects'. What makes a choice impossible is as open to debate as what makes a measure of harm mitigation infeasible. However, unlike 'taking all feasible measures', 'when a choice is possible' does not appear to require a positive causal intervention into the world. The requirement may be satisfied if an attacker, potentially unreasonably, believes that a choice is not possible. A duty of care, in contrast, would be the extraordinarily demanding requirement to explore as many alternative targets as a reasonable observer would consider sufficient to ensure that the chosen target was truly without alternative. ${ }^{29}$ It is highly implausible that Article 57(3) API implies such a second-order duty of care in ruling out alternative targets.

\footnotetext{
${ }^{28}$ The question what makes a measure to reduce incidental civilian harm infeasible evokes similar debates as the question what makes measures infeasible that an attacker has to take to verify the status of a target. For the range of views, see Belt $(2000,174)$, Jaworski $(2003,201)$, Quéguiner $(2006,797)$, Schmitt $(2003,10)$.

${ }^{29}$ This would require nothing less than establishing metaphysical 'lastness'.
} 


\section{A duty of care to ensure the proportionality of civilian harm?}

Let us assume that an attacker meets her duty of care in distinction between persons by taking verification measures sufficient to ensure that she is aiming at a combatant. Even if she then also undertakes verification measures sufficient to ensure that she has ruled out alternative targets and exhausted all feasible precautions to reduce civilian casualties, she may still expect that the weapon will misfire, the military object will move or civilians will be harmed in the blast. Still this would not inevitably be a bar to attack. In other words, even if IHL imposed an implied duty of care in ensuring that incidental harm is necessary I argued that this is highly implausible - a reasonable, non-negligent attacker would still not meet a minimum standard of civilian protection in the attack's outcome.

It is ostensibly the role of the principle of proportionality to secure such a minimum standard of civilian protection in the outcome of an attack. Proportionality decrees that it is not enough that the harmful consequences of a military operation were unavoidable. The relevant provision prohibits attacks that 'may be expected to cause incidental loss of civilian life, injury to civilians, damage to civilian objects, or a combination thereof, which would be excessive in relation to the concrete and direct military advantage anticipated' (Article 51(5) b API). The corresponding second-order duty imposed by Article 57 requires an attacker to do everything feasible to verify that it is not prohibited by the provisions of this Protocol to attack' a given military target (Article 57(2) [i]). This second-order obligation again turns on the feasibility of the effort to establish the proportionality of incidental harm, not on whether this effort is sufficient. A duty of care in ensuring the proportionality of civilian harm would have to be implied.

As a first step, such an implied second-order obligation would require care in forming expectations regarding an attack's military advantage and incidental harm. The demand to 'do everything feasible' certainly means an attacker cannot simply rely on her spontaneous beliefs about the consequences of an attack. The wording 'may be expected' in Article 51(5) b further supports the interpretation that the proportionality judgment has to be made based on the expectations of a reasonable person not simply the actual expectations of the attacker. A duty of care, however, would also entail that, if feasible verification measures leave the attacker without secure expectations regarding the military advantage and the civilian harm an attack will cause, she would not be permitted to launch the attack. What would secure expectations regarding the consequences of an attack mean?

In the case of distinction, a duty of care required that a reasonable observer would be sure that a weapon was not aimed at a civilian. Can we really require the same level of knowledge regarding the military advantage and incidental harm an attack will cause? Reasonable individuals should rarely if ever be certain about the future consequences of their conduct. IHL does not mention the chances of an attack's military success, but could a military advantage not reasonably be considered 'anticipated' if it is only $85 \%$ likely to materialize? Similarly, incidental harm to civilians as a side-effect of an attack could be $75 \%$ likely to occur and it would be reasonable to consider it 'expected'. This interpretation suggests that compliance with the principle of proportionality itself requires not only an 
estimation of the magnitude or significance of the attack's expected effects, but also of their probability.

An estimation of the likelihood of an attack's consequences is thus part of an attacker's first-order duty. A second-order duty of care in discharging proportionality would then demand that an attacker only launches an attack if a reasonable observer would be confident in her calculation that $\mathrm{x}$ number of civilian casualties are $\mathrm{x} \%$ likely to occur. ${ }^{30}$ It is contestable, but not implausible, that Article 57(2) [i] implies such a duty of care in ensuring that the attacker's expectations about the consequences of an attack are sound.

As a second step, a duty of care in ensuring the proportionality of civilian harm could concern the excessiveness judgment itself. Complying with the principle of proportionality requires more than just secure knowledge about the intended and unintended consequences of an attack. It also requires a competent judgment about how these consequences, that is military progress and loss of civilian life, relate to each other. Let us assume an attacker has sound expectations regarding the magnitude and likelihood of the incidental harm an attack will cause and the military advantage it will yield. Does she have a duty to verify her judgment about whether or not the expected incidental harm is excessive? If, for instance, I know I am bad at making proportionality judgments, do I have an additional obligation to seek assistance, to 'do everything reasonably sufficient' or even just 'everything feasible' to make my judgment competent? And would I have to refrain from attacking if a reasonable observer would retain doubts about my proportionality judgment, for instance, because I am in a state of diminished competence due to fear or stress?

For us even to know what it means to exercise care in making a proportionality judgment we have to take a closer look at what it means to weigh civilian life and military advantage, two ostensibly 'dissimilar' values (Schmitt 2002, 8). References to proportionality or indeed the task of comparing seemingly in-commensurate values are not unusual in law. There are two ways in which we can approach such a task. One is to ask again what the reasonable observer would consider to be proportionate or 'a proper balance'. In both tort and criminal law this is a common way of assessing an individual's judgments about whether an outcome is excessive, fair or equitable. For this particular judgment this approach is, however, of limited usefulness. Empirical research suggests that observers only agree in their assessment of easy cases. In fact, even individuals with military expertise have widely diverging reactions to most attacks that cause some incidental harm and yield some military advantage. ${ }^{31}$

An alternative way of assessing the relationship between ostensibly dissimilar values is by converting one value into the other or by identifying a common metric. In some cases, it may be possible to express an anticipated military

\footnotetext{
${ }^{30} \mathrm{We}$ could, of course, manipulate what it takes to obey this duty of care. Namely, we could increase the confidence of the reasonable observer in our projection of an attack's consequences by reducing the probability we assign to their emergence. For instance, if a reasonable observer would be only $60 \%$ confident that I am right in thinking there is an $80 \%$ chance of a military advantage, they might be $100 \%$ confident in a $60 \%$ probability. At the same time, if I have to discount the expected military advantage by a factor of 0.6 rather than 0.8 , the expected civilian casualties might turn out to be excessive.

${ }^{31}$ See Dunlap (2001), Fenrick $(2004,189)$, Statman et al. under review.
} 
advantage in terms of civilian lives saved, but often it will not. ${ }^{32}$ Is there a common metric for military advantage and incidental loss of civilian life? In tort law, monetary value is often used as a common metric. Though difficult to establish, loss of human life can theoretically be expressed in terms of economic damage, for instance, lost earning potential. This may be distasteful, but with the understanding that it does not express the 'true value' of human life, it is not unusual. However, progress toward military victory in war may well imply a destruction of wealth rather than a monetary gain that could 'outweigh' the loss of human life. If both consequences have negative monetary value, it is not possible for one to balance out the other.

A more adequate measure for expressing loss of life and injury to the human person is moral value. A moral evil can only be justified with the achievement of a moral good or the avoidance of an even greater evil. Can we determine the extent to which a military advantage presents a moral good? If a belligerent is fighting for a morally important war aim, it is in principle possible to express military advantage in terms of progress toward the achievement of this aim. ${ }^{33}$ As Thomas Hurka puts it, 'a war has certain just aims (...) the goods involved in achieving those aims count toward its proportionality' (Hurka 2005, 40). However, IHL envisages that an individual fighting for an unjust aim, for instance as part of an unjust aggression, also makes a judgment as to whether the expected loss of civilian life is excessive in relation to an attack's anticipated military advantage. Just as military advantage in war will often signal the destruction of wealth, it will often amount to progress towards a morally unjust aim. In those cases, there is no metaphysical balance between military advantage and incidental civilian harm because both have a negative value.

Even if there was a point at which incidental harm was proportionate to a military advantage (expressed in terms of progress towards a morally just aim), the epistemic challenges to locating that point would be immense. An attacker would have to correctly judge the moral importance of her party's war aim. She would then have to express the anticipated military advantage, which may well be articulated at the operational or even tactical level, in terms of progress towards this aim. How much moral weight does one air strike have in an overall quest to repel an unjust aggression? For the individual with reasonably good moral judgment, normal cognitive abilities, and average foresight it may systematically be too difficult to accomplish this 'translation' exercise. The above-mentioned lack of agreement even among experts likewise suggests that the law's epistemic demands are intractable.

Crucially, IHL actually envisages that an attacker does not refer to the overall aim of a war, its moral, economic, or political importance, when determining the military value of an attack. Most wars, of course, pursue moral, political, or economic aims, beyond 'mere' military victory. However, IHL has to be applied without regard to the causes or aims of the warring parties. ${ }^{34}$ Progress toward military victory is therefore the only appropriate frame of reference for

\footnotetext{
${ }^{32}$ For this innovative suggestion, see Haque (2017). Under certain circumstances, Haque also allows for combatants' lives saved to count as a good in the proportionality calculus.

${ }^{33}$ This is the dominant approach to proportionality judgments among revisionist just war theorists. Most prominently, Fabre $(2012,6)$, McMahan $(2015,1)$.

${ }^{34}$ Preamble of the First Additional Protocol.
} 
determining whether an attack yields a military advantage and how weighty this is. At the same time, loss of civilian life cannot be expressed in terms of progress toward military victory. After all, civilians are immune from intentional attack based on the assumption that they do not directly contribute to hostilities. Their deaths are militarily neutral.

There are good reasons for the independence of IHL from the moral, political, or economic aims of a belligerent's resort to force. If IHL permitted individual attackers to inflict harm proportionate to the justice and importance of her party's aims, IHL would likely be an ineffective restraint. Most non-coerced combatants in most wars believe that their aims are just and important. ${ }^{35}$ The independence of IHL's permissions from a war's aims is also necessary for upholding the formal legal equality among belligerents. If IHL tied its permissions to whether or not a party's aims are just, it would be unlikely to secure compliance on the 'unjust side'. Nevertheless, the price we pay for IHL's independence from belligerents' war aims is the impossibility of converting military advantage into moral value and to thereby invest with meaning the notion of a balance between incidental civilian harm and military advantage.

To recapitulate, it is plausible to argue that the First Additional Protocol demands that an attacker takes measures that are sufficient to ensure that an attack is not directed against civilians. IHL establishes a duty of care in distinction between persons, but not between objects. IHL does not explicitly impose a duty of care in ensuring the necessity of incidental harm and it is highly implausible that such a duty is implied. Moreover, it is plausible though contestable that Article 57 implies an obligation to take not only feasible, but also sufficient measures to ensure sound expectations about an attack's consequences. At the same time, nothing in the law indicates that an attacker also has to take steps to verify their judgment of whether the reasonably expected civilian harm is proportionate to the reasonably anticipated military advantage. The proportionality judgment itself is not subject to a second-order duty of care.

If the meaning of excessive incidental civilian harm were self-evident, such a second-order duty to take care in judging proportionality would be superfluous. If it were difficult to determine where the balance is between loss of civilian life and military advantage, a duty of care would be crucial in order to ensure that civilians benefit from the effective, if limited, protection of IHL. ${ }^{36}$ In fact, where incidental civilian harm and military advantage are in proportion is neither self-evident nor difficult to establish. It is impossible to strike such a balance because IHL does not permit that military advantage is determined in terms of a metric or value that we can also use to weigh the loss of civilian life. It is therefore not simply uncertain how hard the attacker has to try to avoid the harmful outcome that the engagement of the enemy risks causing. It is uncertain what exactly that outcome is.

\section{The mens rea of unlawful attack}

The purpose of a duty of care is not only to guide the agent in her efforts to comply with her first-order duties. It is also a means of establishing ex post facto

\footnotetext{
${ }^{35}$ For this argument, see also Dill (2013), Shue (2010, 87).

${ }^{36} \mathrm{~A}$ duty of care in making a proportionality judgment could, for instance, imply the requirement of a deliberation or consultation to verify an attacker's excessiveness judgment.
} 
responsibility. As a duty of care is an obligation to mitigate unintended consequences, to avoid mistakes or accidents with a view to securing a specified outcome, its imposition often signals that negligence or recklessness are a sufficient mens rea for responsibility after the fact. ${ }^{37}$ This raises the question of what the required mens rea is for unlawful attack. Can ICL remedy some of the uncovered uncertainty in the interpretation of Article $57 ?^{38}$ The absence of criminal responsibility for negligent or reckless violations of certain provisions under IHL would not necessarily support the position that attackers do not incur a duty of care. Negligent or reckless failure to properly verify the status of a target could be illegal without being criminal. The reverse, however, is not possible. If international criminal jurisprudence did embrace criminal negligence or recklessness, this would be an argument for IHL's implying a duty of care in attack.

What would it look like if ICL recognized negligence or recklessness as a mens rea for unlawful attack? An actor is criminally negligent when he 'should be aware of a substantial and unjustifiable risk that the material element [of a crime] exists or will result from his conduct', but he fails 'to perceive the risk' (Fletcher 2012, 1736). This failure must involve 'a gross deviation from the standard of care that a reasonable person would observe in the actor's situation'. ${ }^{39}$ A reckless actor, to the contrary, perceives the risk of harmful consequences, but decides to run it (Fletcher 2012, 1723). Let us imagine that an attacker does not have secure expectations regarding the outcome of an attack, for instance, because feasible measures are insufficient to formulate such expectations. If negligence is the required mens rea, the attacker will automatically be responsible for any unnecessary or excessive civilian harm she causes. For recklessness, it would have to be shown that she was actually aware of her measures being insufficient to create sound expectations. She would have to be aware of the risk that her attack would result in unnecessary or excessive civilian harm.

The International Criminal Tribunal for the former Yugoslavia (ICTY) is so far the only international forum to have widely and systematically attempted to hold individuals responsible for unlawful attacks directly in virtue of international law. ${ }^{40}$ After the tribunal declared the mens rea for the crime of unlawful attack to be

\footnotetext{
${ }^{37}$ In tort law, a duty of care is usually mirrored in negligence. In criminal law, however, negligence as a mens rea is rare and controversial. Criminality is considered to be based on the unity of actus reus and mens rea, meaning unlawful conduct or consequences are brought about with a 'guilty mind'. Some scholars argue that negligence is not a state of mind, but the absence of awareness of wrongdoing. As this section is concerned with criminal law, it therefore extends the investigation to recklessness as a mens rea that could corroborate that an attacker incurs a duty of care.

${ }^{38} \mathrm{IHL}$ imposes duties on both the individual combatant and the belligerent party. This paper is interested in the competing demands on law to do justice to the individual agent in war. It therefore focuses on individual responsibility under ICL rather than on state responsibility.

${ }^{39} \$ 2.02(2)(\mathrm{d})$ Model Penal Code.

${ }^{40}$ The resolution that determines the ICTY's jurisdiction ratione materiae criminalizes certain breaches of the four Geneva Conventions and the laws and customs of war, but does not mention API. The latter contains the principle of proportionality and the prescription to take precautions in attack. However, the Appeals Chamber in the Tadic decision interpreted 'laws and customs of war' to include treaties to which the states in question were party at the time of the alleged crime. As a result, the case law extensively features references to the principles of necessity and proportionality. See, among others, Prosecutor v. Galic, Judgment of the Appeals Chamber of 30 November 2006, IT-98-29-A, \$142; Prosecutor v. Galić, Judgment of the Trial Chamber of 5 December 2003, IT-98-29-T, \$58.
} 
willfulness, which includes 'intention or recklessness not simple negligence,, ${ }^{41}$ the judges in the Galić case argued that a commander incurs responsibility if she 'was aware or should have been aware of the civilian status of the persons attacked'. ${ }^{42}$ This formulation alludes, on the one hand, to knowledge (was aware of the civilian status) and, on the other hand, to negligence (should have been aware of the civilian status, but was not). A formulation affirming criminal recklessness would be that the attacker 'was aware of the risk that the persons attacked were civilians'. This is the threshold for liability that the Appeals Chamber endorsed in the Blaškić case: the defendant incurs criminal liability if he was aware of the 'substantial likelihood' that the actus reus of the crime would occur. ${ }^{43}$

The diverging language across these cases notwithstanding, the ICTY's jurisprudence lends considerable support to the argument that individual attackers have a second-order duty of care in distinction. This means that an insufficient effort to verify the status of a target can render attacking a civilian a criminal offense even if it was not done intentionally. In turn, if an attacker could not create reasonable certainty regarding the status of a target, she should not have launched the attack. Whether the attacker has to have been aware of this insufficiency of information and the attending risk (recklessness), or whether it is enough that she failed to clear the bar of reasonable certainty about the status of her target (negligence), remains contestable. Notably, the Rome Statute backtracks from the ICTY's occasionally tentative, but generally solid affirmation that an attacker can violate distinction recklessly and potentially even negligently, leaving the scope of ex post facto individual criminal responsibility for violations of distinction fragmented and contestable. ${ }^{44}$

What about the outcome of an attack? Section III of this paper argued that it was implausible that an attacker could violate the principle of necessity by failing to achieve reasonable certainty that incidental harm was truly unavoidable and a target without alternative. Section IV found plausible, but contestable, that an attacker could violate the principle of proportionality by not establishing sound expectations regarding the likelihood and magnitude of the military advantage and the civilian harm resulting from an attack. The following paragraphs will show that, when it comes to these principles and hence the consequences of an attack, the ICTY has proven faithful to its own dictum that negligence is not enough for criminal responsibility. Although it has lent some support to the argument that reckless violations of the principle of proportionality can trigger criminal responsibility, this support is equivocal.

For the determination of whether an attacker violated the principle of proportionality, the Trial Chamber in the Galić case specified that it was 'necessary to examine whether a reasonably well-informed person in the circumstances of the actual perpetrator, making reasonable use of the information available to him or

\footnotetext{
${ }^{41}$ Final Report to the Prosecutor by the Committee Established to Review the NATO Bombing Campaign Against the Federal Republic of Yugoslavia, 8 June 2000. For the most comprehensive discussion of the understanding of intent in international criminal jurisprudence, see Ohlin (2013b).

${ }^{42}$ Galić, Judgment of the Trial Chamber, $\$ 55$.

${ }^{43}$ Prosecutor v. Tihomir Blaškić, Judgment of the Appeals Chamber of 29 July 2004, IT 95-14-A, \$\$41f.

${ }^{44} \mathrm{An}$ analysis of the criminalization of unlawful attack in the ICC Statute is beyond the scope of this paper. For discussions of the fragmentation in the mental element of crimes of unlawful attack, see also Dormann (2003, 132), Haque (2011), Schabas (1998, 419), Werle and Jessberger $(2005,54)$.
} 
her, could have expected excessive civilian casualties to result from the attack'. ${ }^{45}$ The fact that the standard is 'a reasonably well informed person', may suggest that if it is impossible to acquire information to become 'reasonably well informed', launching an attack would be prohibited. At the same time, the chamber emphasized that it was the information available to the attacker in the circumstances that counts. That the chamber raised the question whether this information in fact allowed the attacker to expect excessive civilian harm undermines the argument that there is an objective minimum standard of knowledge about the consequences of an attack that an attacker has to meet in order to be permitted to release her weapon.

In the same case the Trial chamber referred back to the 'circumstances of an attack' stating that to be criminally responsible an attacker must have created excessive incidental harm 'willfully and in knowledge of circumstances giving rise to the expectation of excessive civilian harm' 46 'Knowledge of circumstances' could mean that a reasonable attacker could have known an attack was likely to cause excessive harm. On its own, this does not imply the attacker indeed had any inkling of the likely consequences of her attack. Yet, according to the judgment an attacker has to have acted not only in the knowledge of the circumstances, but also willfully, which at minimum means recklessly. This in turn requires actual awareness of the risk of excessive civilian harm. An attacker who is unreasonably unaware of the likely consequences of an attack would not be criminally responsible for excessive civilian casualties in this reading.

If willfulness includes recklessness anyway, why does the Galić judgment require an actor's having knowledge of the circumstances giving rise to the expectation of excessive civilian harm alongside willfulness? As suggested above, knowledge of the circumstances could simply be an indication that it was not impossible for a reasonable attacker to have expected the excessive incidental harm. However, this is already implied by the requirement of willfulness. Alternatively, 'knowledge of the circumstances' could also be taken to mean that the chamber inferred that an attacker who had knowledge of the circumstances actually did expect disproportionate civilian harm. In other words, knowledge of the circumstances would be considered evidence, not just of unreasonable (reckless) risk-taking, but of an attacker's knowledge that she would cause excessive incidental harm. This would set the standard for a criminal violation of proportionality at knowledge, hence higher than just recklessness.

Would knowing rather than just 'assuming the risk' of excessive civilian casualties not mean an attacker also violated the principle of distinction? It only makes sense to claim that an attacker acted in the knowledge that civilians would die as a result of her attack, but she did not intend to kill them, if we adopt an attitudinal rather than a cognitive definition of intent. ${ }^{47}$ An attitudinal approach hinges intent on what an actor wants or desires. Most common law approaches, however, consider intent to be what the actor knows will happen as a consequence of her conduct. In this case intent (she has the expectation of excessive civilian harm) is on a continuum with recklessness (she knows it is likely that the attack will cause excessive incidental harm). According to this cognitive understanding of

\footnotetext{
${ }^{45}$ Galić, Judgment of the Trial Chamber, $\$ 58$.

${ }^{46}$ Id., $\$ 59$.

${ }^{47}$ For a comparison of these two understandings of intent, see Fletcher $(2012,1832 \mathrm{ff})$.
} 
intent, it would be impossible to claim that an actor knew with equal certainty that an attack would destroy a military objective and cause civilian harm in the process, but she only intended the former and was reckless regarding the latter.

The previous section also argued that it is impossible, on the law's own terms, to establish whether or not incidental harm is excessive. The ICTY's jurisprudence likewise corroborates this argument as chambers consistently avoid concretizing what proportionate incidental civilian harm looks like. ${ }^{48}$ Several judgments, for instance, assert the relevance of the principle of proportionality and define it in the abstract without at all applying the principle to the facts. ${ }^{49}$ Other judgments make findings based on proportionality, but fail to engage in what would amount to balancing military advantage against incidental civilian harm. ${ }^{50}$ The Trial Chamber in Prosecutor v. Boškoski and Tarčulovski followed a statement that an attack must not be disproportionate with the elaboration: 'In other words, unnecessary or wanton use of force against property is prohibited' ${ }^{51}$ In this reading, once the expected incidental harm cannot be lowered any further (it is necessary), the attack is considered proportionate. ${ }^{52}$ This statement collapses proportionality into necessity.

The case law comes closest to featuring actual enquiries into the proportionality of an attack in the Galic and Gotovina cases. The former judgment raised the question whether a fifty-fifty distribution of civilian and military casualties would constitute a disproportionate attack. ${ }^{53}$ The Trial Chamber further hypothesized that 'an attack on a crowd of approximately 200 people, including numerous children, would be expected to cause' excessive loss of life. ${ }^{54}$ At the same time, the judges failed to clearly identify the military advantage at stake. At the end, the defendant was found guilty of directing an attack against civilians, hence of violating the principle of distinction. ${ }^{55}$ In the Gotovina case, the Trial Chamber found that the attack in question 'created a significant risk of a high number of civilian

\footnotetext{
${ }^{48}$ Rather than attempting to translate military advantage and excessive harm into a common metric, the ICTY clearly draws on the reasonable observer approach. Indeed, the chambers refer to the judgment of a 'reasonable military commander' as the benchmark for what is excessive civilian harm. For a discussion of this concept, see Duttwiler $(2006,6)$.

${ }^{49}$ These include Prosecutor v. Kupreškic and Others, Judgment of the Trial Chamber of 14 January 2000, IT-95-16-T; Prosecutor v. Strugar, Judgment of the Trial Chamber of 31 January 2005, IT-01-42-T, \$\$281 and 295; Prosecutor v. Strugar, Judgment of the Appeals Chamber of 17 July 2008, IT-01-42-A, \$179; Prosecutor v. Martic, Trial Chamber Review of the Indictment pursuant to Rule 61 of the Rules of Procedure and Evidence of 8 March 1996, IT-95-11-R61; Prosecutor v. Dragomir Miloševic, Judgment of the Trial Chamber of 12 December 2007, IT-98-29/1, \$949.

${ }^{50}$ Prosecutor v. Blaškic, Judgment of the Trial Chamber of 3 March 2000, IT-95-14-T, \$651; Prosecutor v. Milutinovic and Others, Judgment of the Trial Chamber of 26 February 2009, IT-05-87-T, \$920; Prosecutor v. Đordevic, Judgment of the Trial Chamber of 23 February 2011, IT-05-87/1-T, $\$ 980$.

${ }^{51}$ Prosecutor v. Boškoski and Tarčulovski, Judgment of the Trial Chamber of 10 July 2008, IT-04-82-T, $\$ 357$.

${ }^{52}$ If an attack is wanton and directed against an object, it arguably also violates the principle of distinction, because a wanton attack yields no military advantage. If the engagement of an object does not yield a military advantage, the object of attack does not qualify as a military objective in the meaning of Article 52(2) API and the attack violates the principle of distinction.

${ }^{53}$ Galić, Judgment of the Trials Chamber, $\$ 386$.

${ }^{54}$ Id. $\$ 382$.

${ }^{55}$ The Appeals Chamber (Galić, Judgment of the Appeals Chamber, $\$ \$ 187 \mathrm{f}$ and 192) declined to reconsider the issue of proportionality because the conviction had occurred on the grounds of a failure to distinguish.
} 
casualties'. It further stated that 'this risk was excessive in relation to the anticipated military advantage of firing at the two locations' ${ }^{56}$ At the same time, the chamber did not explicitly elaborate what the military advantage of the attacks might have been. The Appeals Chamber accordingly criticized that the judgment 'was not based on a concrete assessment of comparative military advantage'. Gotovina and his co-defendants were acquitted.

Rather than being the element of an independently justiciable crime of unlawful consequences, large numbers of civilian casualties have had an evidentiary role in convictions for criminal violations of distinction. ${ }^{58}$ Several judgments feature the assertion that 'certain apparently disproportionate attacks may give rise to the inference that civilians were actually the object of attack'. ${ }^{59}$ The Appeals Chamber in the Milošević case most explicitly admitted to the relegation of proportionality to an indicator for intent not to distinguish. After branding as 'confusing' the language of the Trial Chamber regarding whether victims of an attack were incidental victims or the unlawful targets of an attack, ${ }^{60}$ it stated that 'due to its disproportionate and indiscriminate nature, it (the attack) was unlawfully directed against the civilian population'. ${ }^{61}$ Crucially in this latter case, civilian casualties are not used as an indicator for negligence or even recklessness in distinction, that is for unreasonable risk-taking. They are presumed to have been brought about deliberately. $^{62}$

The conclusion is inescapable that the ICTY equivocates regarding the expectations an attacker has to have about the consequences of an attack in order to avoid criminal responsibility. The resulting fragmentation of the mens rea for unlawful attack buttresses the above argument that there is room for contestation as to whether IHL implies a second-order duty of care in ensuring that expected incidental harm is necessary and proportionate. Furthermore, the failure of the judges to systematically compare the anticipated military advantage of an attack to the expected civilian casualties, supports the contention detailed in section IV: it is fundamentally unclear what unlawful consequences of an attack during the conduct of hostilities look like.

\footnotetext{
${ }^{56}$ Prosecutor v. Gotovina, Čermak and Markač, Judgment of the Trial Chamber of 15 April 2011, IT-0690-T, $\$ 1910$.

${ }^{57}$ Prosecutor v. Gotovina, Črmak and Markač, Judgment of the Appeals Chamber of 16 November 2012, IT-06-90-A, \$82.

${ }^{58}$ For the argument that the appropriate role of the principle of proportionality is to ground a defense or justification rather than a crime in its own right, see Haque (2010).

${ }^{59}$ Galić, Judgment of the Trials Chamber, \$60; also, Martić, Judgment of the Trial Chamber, $\$ 69$. 'Apparently' does not refer to the possibility of foreseeing the damage, but to the extent of the excessiveness of civilian harm. Of course, only 'apparently disproportionate' attacks would ever come before the ICTY, in the first place.

${ }^{60}$ Prosecutor v. Milošević, Judgment of the Appeals Chamber of 12 November 2009, IT-98-29/1-A, \$55

${ }^{61}$ Id., $\$ 264$

${ }^{62}$ Prosecutor v. Popović et al., Judgment of the Trial Chamber of 10 June 2010, IT-05-88-T, \$775; likewise, Prosecutor v. Boškoski and Tarčulovski, Judgment of the Appeals Chamber of 19 May 2010, IT-0482-A. In the appeal the defendant submitted that the Chamber had 'failed to consider what would constitute proportionate behaviour' (\$39). However, the Prosecution held that the civilian victims clearly were the object of the attack $(\$ 42)$ and the Appeals Chamber concurred ( $\$ 46)$.
} 


\section{The limits to the individualization of war}

So far, this paper presented two arguments. First, from an individualist point of view, a duty of care in attack is morally ambivalent. Second, there is considerable uncertainty and room for contestation regarding the second-order duties that Article 57 actually imposes. They fall short of a comprehensive duty of care in attack. It is beyond the scope of this paper to investigate systematically whether the moral ambivalence and the uncovered legal uncertainty surrounding the duty of care in attack are connected. It is worth remembering though, that the individualization of war is not only a moral goal that law ought to pursue. It is an observable multi-dimensional norm-shift in international relations, which creates a political imperative for IHL to effectively address and benefit the individual. This political imperative, buttressed by its moral plausibility, is bound to shape purposive interpretations of IHL. That the individualization of war creates strong reasons both for and against a legal duty of care may therefore contribute to the legal contestation of the open-ended provisions of Article 57.

In testament to the moral appeal and political momentum of the individualization of war, critics of the corresponding legal developments tend not to contest the appropriateness of law's addressing or benefiting the individual. Instead, they highlight IHL's other regulative goal and the corresponding pragmatic imperative against enhancing the protections that IHL affords individuals in war: Law should not make waging war prohibitively difficult for the state belligerent, lest it be ignored. IHL's rules for the conduct of hostilities in particular must balance humanitarian concerns with military pragmatism in order to attract compliance. ${ }^{63}$ In this familiar reading, IHL faces a trade-off between the individual's interest in being shielded from the harmful effects of combat - a central quest in the individualization of war - and the state belligerent's interest in overcoming the enemy.

This paper uncovered a different, much less appreciated trade-off. The progressive individualization of war is not only limited by a countervailing imperative not to curtail the state's freedom of action. IHL faces a trade-off in the individualization of war itself. This presents a more fundamental dilemma than IHL's need to balance humanitarianism, which benefits the individual, with military pragmatism, which appeals to the state. The urgency of this familiar dilemma is contingent on the institutional development of the international legal order and the strength of IHL's compliance pull. The more incentives for compliance legal institutions afford, the less IHL has to forego protecting the individual in order to accommodate states' interests. In contrast, the dilemma that IHL faces in the individualization of war itself is rooted in the non-contingent reality of war. As long as war systematically impairs the individual attacker's moral agency, its individualization is limited.

That is not to say that the individualization dilemma cannot be mitigated. It is more or less acute depending on how severely the individual combatant's moral agency is in fact impaired. To recall, moral agency had three dimensions: the capacities to tell right from wrong, to apply this judgment to the situation at hand, and to act according to one's own reasons. Combatants higher up in the chain of command, for instance, may be removed from the immediate stresses of battle and

\footnotetext{
${ }^{63}$ Amongst others, Jaworski (2003), Sandoz et al. (1987), Schmitt (2010). For a comprehensive discussion of the role of the balance metaphor in the regulation of warfare, see Ohlin and May $(2016, \mathrm{ch} .7)$.
} 
therefore better retain their capacity to tell right from wrong. Such commanders are also less constrained by the military hierarchy and therefore more often able to act according to their own reasons. Affirming a duty of care in the decisions that military commanders make is therefore less problematic. At the same time, increasing the effort and attention that military commanders have to invest in discharging their first-order obligations offers only a limited solution to the problem. It is, after all, the actions of the 'trigger pullers' on the ground that most immediately affect civilians.

Similarly, some means of stand-off warfare allow a combatant's ability to tell right from wrong to remain intact. During an air strike, for instance, the attacker is rarely in mortal danger. At the same time, stand-off warfare may add to the impairment of the second dimension of an attacker's moral agency, that is the ability to apply this judgment to the situation at hand. Attacking from the air can reduce the situational awareness that allows an individual to understand and estimate the consequences of her conduct. Developments in the means and methods of warfare may nonetheless contribute to mitigating the individualization dilemma in as much as they systematically reduce the impairment of attackers' moral agency. As long as warfare remains a large-scale collective exchange of violence, however, the dilemma that law faces between giving the individual attacker and the individual civilian her legal due is unlikely to be fully overcome.

The intractability of the trade-off in the individualization of war raises the question of whether Article 57 offers the best possible legal compromise between effectively guiding IHL's main addressee (combatants acting as attackers) and protecting its main beneficiary (civilians). The above conclusion that the duties enshrined in Article 57 do not amount to a comprehensive duty of care may suggest that IHL prioritizes the interests of the attacker over those of the civilian. Negotiation records indeed indicate that the choice of 'feasibility' as a standard reflects a concern among the drafters that attackers would be held to account for battlefield outcomes over which they have limited control. ${ }^{64}$ At the same time, the previous section showed that the open-endedness of Article 57 does not in fact benefit the attacker. It does not limit the scope of ex post facto responsibility in a systematic fashion. Instead, the fragmentation in the mens rea that Article 57 invites undercuts the individual attacker's security of expectations. Rather than lowering the expectations for conduct ex ante, a better and more common response to impaired moral agency in criminal law is to count the impairment, in accordance with its actual severity in the moment, as an excuse or defense after the fact (Fletcher 1998, 99; Honoré 1999, 77).

Before an attack, uncertain and contestable second-order duties do not serve combatants' interests either. In situations in which it is systematically difficult to tell right from wrong, law has two alternative responses. ${ }^{65}$ Law can slow down decision-making, for instance by demanding additional information, a deliberation in good faith or external guidance. Alternatively, in situations also characterized by urgency to decide, law must be easy to apply and easy to act on. Article 57 and the

\footnotetext{
${ }^{64}$ Official Records of the Diplomatic Conference on the Reaffirmation and Development of International Humanitarian Law Applicable in Armed Conflicts (1978), Volume XV, 285.

${ }^{65} \mathrm{Law}$ can also recognize individuals as limited subjects if their ability to tell right from wrong is systematically reduced, for instance, children or the insane. This is not an option where combatants in war are concerned.
} 
determination of 'feasibility' that it requires, in contrast, require a future oriented judgment the parameters of which are subject to controversy. Even if it were clarified what makes a measure infeasible, an attacker would still have to overcome considerable epistemic challenges in order to meet her second-order obligations. Finally, after overcoming these epistemic challenges, even an unimpaired moral agent cannot, on the law's own terms, determine the outcome that the reasonable attacker ought to strive for. With Article 57, IHL not only falls short in relieving the attacker 'of the cognitive burdens of forming her own judgments' (Habermas 1996, 115). It asks for an impossible judgment.

In sum, the second-order duties enshrined in Article 57 may not be so strict as to prevent an attacker from launching the attacks that a state belligerent might wish her to carry out. Precautions in attack do not undercut IHL's objective to allow combat to proceed. The provision affords a compromise in the familiar trade-off between humanitarianism and military pragmatism. However, Article 57 is almost certainly too strict in its cognitive demands on the attacker. The provision imposes these burdens on the impaired moral agent without reaping the protective benefits of a duty of care for civilians. As such, it is not at all a compromise between the interests of the individual addressee of IHL's guidance (combatants acting as attackers) and the interests of the individual beneficiary of its protections (civilians). It is an opportunity missed to articulate what such a compromise might look like. The standard legal responses to impaired moral agency - clear, actionguiding second-order duties ex ante and the recognition of impairment as a defense ex post - may serve as inspiration for what a better response might look like to the trade-off that IHL faces in the individualization of war.

Acknowledgment. For comments on earlier drafts, the author would like to thank Alejandro Chehtman, Cécile Fabre, Aeyal Gross, Adil Haque, Eliav Lieblich, Jeff McMahan, Jonathan Parry, Michael Robillard, Cheyney Ryan, Henry Shue, Victor Tadros, Patrick Tomlin, and Robert Underwood. All remaining errors are, of course, the author's own.

\section{References}

Belt, Stuart W. 2000. "Missiles Over Kosovo: Emergence, Lex Lata, of a Customary Norm Requiring the Use of Precision Munitions in Urban Areas." Naval Law Review 47:115-75.

Berster, Lars C. 2010. "'Duty to Act' and 'Commission by Omission' in International Criminal Law." International Criminal Law Review 10:619-46.

Blum, Gabriella. 2014. "The Individualization of War: From War to Policing in the Regulation of Armed Conflicts." In Law and War, edited by Austin Sarat, Lawrence Douglas, and Martha Merrill, 48-83. Stanford, CA: Stanford University Press.

Blum, Gabriella. 2010. "The Dispensable Lives of Soldiers." Journal of Legal Analysis 2:69-124.

Bohrer, Ziv. 2012. "The Superior Orders Defense: A Principal Agent Analysis." Georgia Journal of International and Comparative Law 41:1-74.

McBride, Nicholas J., and Bagshaw, Roderick. 2005. Tort Law. Harlow, UK: Pearson Longman.

Crawford, Neta. 2013. Accountability for Killing: Moral Responsibility for Collateral Damage in America's Post-9/11 Wars. Oxford, UK: Oxford University Press.

Dill, Janina. 2013. "Should International Law Ensure the Moral Acceptability of War?" Leiden Journal of International Law 26:253-70.

Dill, Janina. 2015. Legitimate Targets? Social Construction, International Law, and US Bombing. Cambridge, UK: Cambridge University Press.

Dinstein, Yoram. 2016. The Conduct of Hostilities Under the Law of International Armed Conflict. Cambridge, UK: Cambridge University Press. 
Dormann, Knut. 2003. Elements of War Crimes under the Rome Statute of the International Criminal Court: Sources and Commentary. Cambridge, UK: Cambridge University Press.

Droege, Cordula. 2007. "The Interplay Between IHL and IHR in Situations of Armed Conflict." Israel Law Review 40:310-55.

Dumont, Louis. 1986. Essays on Individualism: Modern Ideology in Anthropological Perspective. Chicago, IL: Chicago University Press.

Dunlap, Charles J. 2001. "Law and Military Interventions, Preserving Humanitarian Values in 21st Century Conflicts." Accessed July 27, 2016, http://people.duke.edu/ pfeaver/dunlap.pdf

Duttwiler, Michael. 2006. "Liability for Omission in International Criminal Law." International Criminal Law Review 6:1-61.

Elliott, Michael A. 2007. "Human Rights and the Triumph of the Individual in World Culture." Cultural Sociology 1:343-63.

Fabre, Cécile. 2012. Cosmopolitan War. Oxford, UK: Oxford University Press.

Fenrick, William. J. 2004. "The Prosecution of Unlawful Attack Cases Before the ICTY." Yearbook of International Humanitarian Law 7:153-89.

Fletcher, George P. 1998. Basic Concepts of Criminal Law. Oxford, UK: Oxford University Press.

Fletcher, George P. 2012. "The Theory of Criminal Liability and International Criminal Law." Journal of International Criminal Justice 10:1029-044.

Forsythe, David P. 2006. Human Rights in International Relations. Cambridge, UK: Cambridge University Press.

Goldberg, John C. P., and Zipursky, Benjamin C. 2007. "Tort Law and Moral Luck.” Cornell Law Review 92:1123-176.

Greenwood, Christopher J. 2008. "Historical Development and Legal Basis." In The Handbook of International Humanitarian Law, 2nd ed. edited by Dieter Fleck, 1-42. Oxford, UK: Oxford University Press.

Habermas, Jürgen. 1996. Between Facts and Norms: Contributions to a Discourse Theory of Law and Democracy. Boston, MA: MIT Press.

Haque, Adil A. 2010. "Criminal Law and Morality at War." In Philosophical Foundations of Criminal Law, edited by R. A. Duff and Stuart P. Green, 481-506. Oxford, UK: Oxford University Press.

Haque, Adil A. 2011. "Protecting and Respecting Civilians: Correcting the Substantive and Structural Defects of the Rome Statute." New Criminal Law Review 4:519-75.

Haque, Adil A. 2012. "Killing in the Fog of War." Southern California Law Review 86:63-116.

Haque, Adil A. 2017. Law and Morality at War. Oxford, UK: Oxford University Press.

Honoré, Anthony. 1988. "Responsibility and Luck: The Moral Foundations of Strict Liability." Quarterly Law Review 104:530-53.

Honoré, Anthony. 1999. Responsibility and Fault. London, UK: Hart Publishing.

Hurka, Thomas. 2005. "Proportionality in the Morality of War." Philosophy and Public Affairs 33:34-66.

Hylton, Keith N. 2016. Tort Law: A Modern Perspective. New York, NY: Cambridge University Press.

International Committee of the Red Cross. 1978. Official Records of the Diplomatic Conference on the Reaffirmation and Development of International Humanitarian Law Applicable in Armed Conflicts (1974-1977), Volumes I to XIV.

International Criminal Tribunal for the Former Yugoslavia. 2000. Final Report to the Prosecutor by the Committee Established to Review the NATO Bombing Campaign Against the Federal Republic of Yugoslavia.

Isaac, Tracey. 2011. Moral Responsibility in Collective Contexts. Oxford, UK: Oxford University Press.

Issacharoff, Samuel, and Pildes, Richard. 2013. "Targeted Warfare: Individuating Enemy Responsibility." New York University Law Review 88:1521-599.

Jaworski, Eric. 2003. “Military Necessity' and 'Civilian Immunity': Where is the Balance?” Chinese Journal of International Law 1:175-206.

Luban, David. 2014. "Risk Taking and Force Protection." In Reading Walzer, edited by Yitzhak Benbaji, and Naomi Sussman, 277-301. London and New York: Routledge.

May, Larry. 2007. War Crimes and Just War. New York, NY: Cambridge University Press.

McMahan, Jeff. 2009. Killing in War. Oxford, UK: Oxford University Press.

McMahan, Jeff. 2015. "Proportionality and Time." Ethics 125:1-24. 
Meron, Theodor. 2000. “The Humanization of Humanitarian Law.” American Journal of International Law 94:239-78.

Milanović, Marco. 2016. “The Lost Origins of Lex Specialis: Rethinking the Relationship Between HR and IHL." In Theoretical Boundaries of Armed Conflict and Human Rights, edited by Jens David Ohlin, 78-117. New York, NY: Cambridge University Press.

Ohlin, Jens David. 2013a. “The Duty to Capture.” Minnesota Law Review 97:1268-342.

Ohlin, Jens David. 2013b. “Targeting and the Concept of Intent.” Michigan Journal of International Law 35:79-130.

Ohlin, Jens David, and May, Larry. 2016. Necessity in International Law. Oxford, UK: Oxford University Press.

Parlett, Kate. 2011. The Individual in the International Legal System: Continuity and Change in International Law. Cambridge, UK: Cambridge University Press.

Perry, Stephen R. 1992. “The Moral Foundations of Tort Law.” Iowa Law Review 77:449-514.

Quéguiner, Jean-François. 2006. "Precautions Under the Law Governing the Conduct of Hostilities." International Review of the Red Cross 88:793-821.

Reus-Smit, Christian. 2013. Individual Rights and the Making of the International System. Cambridge, UK: Cambridge University Press.

Sandoz, Yves, Swinarski, Christophe, and Zimmermann, Bruno. eds. 1987. Commentary on the Additional Protocols of 8 June 1997 to the Geneva Conventions of 12 August 1949. Geneva, Switzerland: Martinus Nijhoff Publishers.

Schabas, William. 1998. "General Principles of Criminal Law in the International Criminal Court Statute." European Journal of Crime, Criminal Justice and Criminal Law 4:400-28.

Schmitt, Michael N. 2002. "Ethics and Military Force: The Jus in Bello." Accessed July 27, 2016, https:// www.carnegiecouncil.org/studio/multimedia/20020107/index.html

Schmitt, Michael N. 2003. "The Impact of High and Low-Tech Warfare on the Principle of Distinction." Briefing Paper, Program on Humanitarian Policy and Conflict Research at Harvard University, Boston, MA.

Schmitt, Michael N. 2006. "Precision Attack and International Humanitarian Law." International Review of the Red Cross 87:445-66.

Schmitt, Michael N. 2010. "Military Necessity and Humanity in International Humanitarian Law: Preserving the Delicate Balance." Vanderbilt Journal of International Law 50:795-839.

Shue, Henry. 2010. "Do we Need a Morality of War." In Just and Unjust Warriors: The Moral and Legal Status of Soldiers, edited by David Rodin and Henry Shue, 87-111. Oxford, UK: Oxford University Press.

Sikkink, Kathryn. 2011. The Justice Cascade: How Human Rights Prosecutions are Changing World Politics. New York and London: W. W. Norton and Company.

Statman, Daniel, Sulitzeanu-Kenan, Raanan, and De Wijze, Stephen. under review. "Unreliable Protection: Proportionality in Warfare put to the Test".

Tasioulas, John. 2010. “The Legitimacy of International Law." In The Philosophy of International Law, edited by Samantha Besson and John Tasioulas, 126-50. Oxford, UK: Oxford University Press.

Teitel, Ruti G. 2002. "Humanity's Law: Rule of Law for the New Global Politics." Cornell International Law Journal 35:355-87.

UK Ministry of Defence. 2004. Manual of the Law of Armed Conflict. Oxford, UK: Oxford University Press.

UK, Reservations and Declaration Made on Ratification. 1998. Corrected Letter of 18 June.

Voelz, Glenn J. 2015. “The Individualization of American Warfare.” Parameters 45:99-111.

Waldron, Jeremy J. 1995. "Moments of Carelessness and Massive Loss." In Philosophical Foundations of Tort Law, edited by David G. Owen, 387-409. Oxford, UK: Oxford University Press.

Walzer, Michael. 1977. Just and Unjust Wars: A Moral Argument with Historical Illustrations. New York, NY: Basic Books.

Welsh, Jennifer. 2014. “The Individualization of War: Protection, Liability and Accountability." Trudeau Lecture University of Oxford, Oxford, UK.

Werle, Gerhard, and Jessberger, Florian. 2005. "Unless Otherwise Provided': Article 30 of the ICC Statute and the Mental Element of Crimes under International Criminal Law.” Journal of International Criminal Justice 3:35-55. 
Wolfrum, Rüdiger. 2008. "Enforcement of International Humanitarian Law." In The Handbook of International Humanitarian Law, 2nd ed. edited by Dieter Fleck. Oxford, UK: Oxford University Press. Wright, Jane. 2001. Tort Law and Human Rights. London, UK: Hart Publishing.

\section{Cases and Judgments}

Caparo Industries pIc v. Dickman (1990) 2 AC 605.

Prosecutor v. Martic, Trial Chamber Review of the Indictment pursuant to Rule 61 of the Rules of Procedure and Evidence, March 8, 1996, IT-95-11-R61.

Prosecutor v. Kupreškic and Others, Judgment of the Trial Chamber, January 14, 2000, IT-95-16-T.

Prosecutor v. Blaškic, Judgment of the Trial Chamber, March 3, 2000, IT-95-14-T.

Prosecutor v. Galić, Judgment of the Trial Chamber, December 5, 2003, IT-98-29-T.

The Israel High Court of Justice, Beit Sourik Village Council v. The Government of Israel, Judgment, May 30, 2004, HCJ 2056/04.

Prosecutor v. Blaškić, Judgment of the Appeals Chamber, July 29, 2004, IT-95-14-A.

Prosecutor v. Strugar, Judgment of the Trial Chamber, January 31, 2005, IT-01-42-T.

Prosecutor v. Orić, Judgment of the Trial Chamber, June 30, 2006, IT-03-68-T.

Prosecutor v. Galić, Judgment of the Appeals Chamber, November 30, 2006, IT-98-29-A.

Prosecutor v. Dragomir Miloševic, Judgment of the Trial Chamber, December 12, 2007, IT-98-29/1.

Prosecutor v. Boškoski and Tarčulovski, Judgment of the Trial Chamber, July 10, 2008, IT-04-82-T.

Prosecutor v. Strugar, Judgment of the Appeals Chamber, July 17, 2008, IT-01-42-A.

Prosecutor v. Milutinovic and Others, Judgment of the Trial Chamber, February 26, 2009, IT-05-87-T.

Prosecutor v. Milošević, Judgment of the Appeals Chamber, November 12, 2009, IT-98-29/1-A.

Prosecutor v. Boškoski and Tarčulovski, Judgment of the Appeals Chamber, May 19, 2010, IT-04-82-A.

Prosecutor v. Popović et al., Judgment of the Trial Chamber, June 10, 2010, IT-05-88-T .

Prosecutor v. Đordevic, Judgment of the Trial Chamber, February 23, 2011, IT-05-87/1-T.

Prosecutor v. Gotovina, Čermak and Markač, Judgment of the Trial Chamber, April 15, 2011, IT-06-90-T.

Prosecutor v. Gotovina, Čermak and Markač, Judgment of the Appeals Chamber, November 16, 2012, IT-06-90-A.

Cite this article: Dill, J. 2019. Do attackers have a legal duty of care? Limits to the 'individualization of war'. International Theory 11: 1-25, doi:10.1017/S1752971918000222 